\title{
CYTOPLASMIC-MEMBRANE EGFR PREDICTS EXPANDED RAS MUTATION STATUS IN COLORECTAL CARCINOMAS?
}

\author{
EGFR na membrana citoplasmática prediz a mutação RAS expandida no carcinoma colorretal?

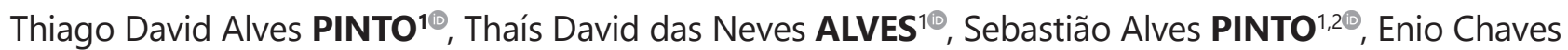 \\ OLIVEIRA $^{3 \odot}$
}

\begin{abstract}
Background: Inhibitors of the epidermal growth factor (EGFR) represent an effective therapeutic option for patients with metastatic colorectal carcinoma, free of activating mutations in KRAS and NRAS. However, the research of mutations is of high cost and scarcely accessible. The expression of the EGFR by immunohistochemistry predicting the mutation status of the expanded RAS (KRAS and NRAS), may allow treatment by a diagnostic method less costly and more accessible. Aim: Investigate the correlation between the clinicalpathological data, the cytoplasmic-membrane expression of the EGFR and the mutational status of the expanded RAS. Method: A total of 139 patients with colorectal carcinoma from the archives of Instituto Goiano de Oncologia e Hematologia were evaluated. Results: Mutation of the expanded RAS was detected in 78 (56.1\%) cases. The EGFR expression was stratified in 23 (16.5\%) "positive", 49 (35.2\%) "negative" and 67 (48.2\%) "uncertain". No significant correlation was found between the mutational status of the RAS and the EGFR expression in comparison to age, gender, location, histological type, histological grade and stage. From 23 "positive" cases, 21 (91.3\%) showed wild-type RAS gene, and 49 "negative", $41(83.7 \%)$ presented mutation, resulting in a strong association between EGFR "positive", "negative" groups and the mutational status of the RAS ( $p<0.001)$, with $86.1 \%$ of accuracy. Conclusions: The cytoplasmic-membrane analysis of the EGFR expression stratified into "positive", "negative" and "uncertain" predicts mutational status of the RAS in $51.7 \%$ of the cases $(p<0.001)$, with $86.1 \%$ of accuracy.

HEADINGS - Colorectal cancer. Ras genes. Mutation. Epidermal growth factor receptor.
\end{abstract}

RESUMO - Racional: Inibidores do fator de crescimento epidermal (EGFR) representam opção de terapia efetiva para o câncer colorrectal metastático, na ausência de ativação de mutações KRAS e NRAS. Entretanto, a pesquisa de mutações é cara e pouco acessível. A expressão de EGFR por imuno-histoquímica predizendo o status mutacional do RAS expandido (KRAS e NRAS) poderia permitir o tratamento por método diagnóstico menos caro e mais acessível. Objetivo: Investigar a correlação entre os dados clinicopatológicos, a expressão de EGFR na membrana citoplasmática e o status mutacional do RAS expandido. Método: Estudo retrospectivo de acurácia envolvendo 139 pacientes com carcinoma colorretal. Resultado: A mutação do RAS expandido foi detectada em 78 (56,1\%) casos. A expressão de EGFR foi estratificada em 23 (16,5\%) casos "positivos", 49 (35,2\%) casos "negativos" e 67 (48,2\%) "duvidosos". Não houve correlação significante entre o status mutacional do RAS e a expressão de EGFR em relação a idade, gênero, local do tumor, tipo histológico, grau histológico e estádio clínico. Em 23 casos "positivos", 21 (91,3\%) mostraram gene RAS tipo selvagem, e em 49 "negativos", 41 (83,7\%) apresentaram mutação, resultando em forte associação entre grupos EGFR "positivo" ou "negativo" e o status mutacional do RAS ( $\mathrm{p}<0.001$ ), com $86,1 \%$ de acurácia. Conclusão: A análise da expressão de EGFR na membrana citoplasmática estratificada em "positivo", "negativo" e "duvidoso" prediz o status mutacional do RAS em $51,7 \%$ dos casos ( $p<0.001$ ), com $86,1 \%$ de acurácia.

DESCRITORES: Câncer colorretal. Genes RAS. Mutação. Receptor de fator de crescimento epidérmico.

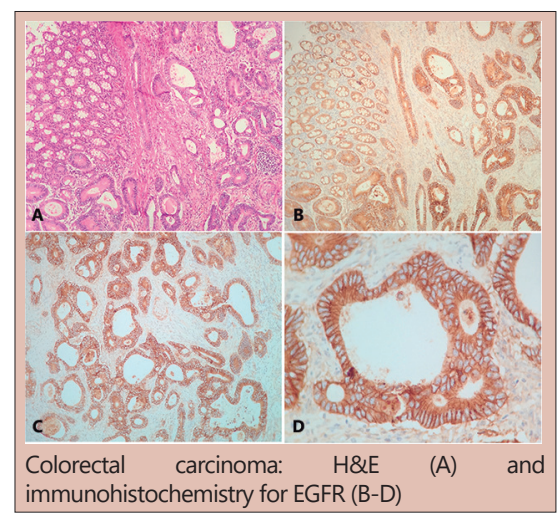

\section{Central message}

This study shows that it is possible to analyze by immunohistochemistry the cytoplasmic-membrane EGFR based in the receptor regulation and, then, classify into "positive", "negative" or "uncertain". It could predict the RAS mutational state in $51.7 \%$ of analyzed cases, with $86.1 \%$ of acuracy $(p<0.001)$.

\begin{tabular}{|l|}
\hline Perspective \\
\hline Immunohistochemistry of cytoplasmic-membrane \\
EGFR based in the receptor regulation classified \\
into "positive", "negative" or "uncertain" can predict \\
the RAS mutational state with $86.1 \%$ of accuracy. \\
Validation by further studies of this proposed score \\
may screen subtypes of colorectal cancer population \\
sensitive to inhibitor-EGFR and promote a fast track \\
to appropriate oncologic treatment. \\
\hline
\end{tabular}

From the ${ }^{1}$ Departamento de Patologia, Instituto Goiano de Oncologia e Hematologia, Goiânia, GO, Brasil; ${ }^{2}$ Departamento de Patologia, Faculdade de Medicina, Universidade Federal de Goiás, Goiânia, GO, Brasil; '²Departamento de Cirurgia, Faculdade de Medicina, Universidade Federal de Goiás, GO, Goiás, Brasil ('Department of Pathology, Goiano Institute of Oncology and Hematology, Goiânia, GO, Brazil; ' ${ }^{2}$ epartment of Pathology, Faculty of Medicine, Federal University of Goiás, Goiânia, GO, Brazil; ${ }^{3}$ Department of Surgery, Faculty of Medicine, Federal University of Goiás, GO, Goiás, Brazil)

How to cite this article: Pinto TDA, Alves TDN, Pinto SA, Oliveira EC. Cytoplasmic-membrane EGFR predicts expanded ras mutation status in colorectal carcinomas? ABCD Arq Bras Cir Dig. 2021;34(1):e1574. DOI: /10.1590/0102-672020210001e1574

\section{Correspondence:}

Enio Chaves Oliveira

E-mail: eco1.br@gmail.com
Financial source: The immunohistochemistry reaction was funded by Instituto Goiano de Oncologia e Hematologia, using subsided inputs directly to this research by DAKO do Brasil.

Conflict of interest: none

Received for publication: 09/06/2020

Accepted for publication: 18/09/2020 


\section{NTRODUCTION}

T he first drug with proven action to treat advanced colorectal cancer (CRC) was the 5-fluorouracil. Posteriorly, the association with leucovorin improved the outcomes. Some years ago, two new drugs were added to the treatment protocols: irinotecan and oxaliplatin. Recently two new classes of biological agents were developed to treat colorectal cancer targeting the Vascular Endothelium Growth Factor (VEGF) and Epidermal Growth Factor Receptor $(E G F R)^{18}$. Many factors associated to survival (prognostic biomarkers) and factors able to identify patients with low or higher probability to get a benefit from particular treatment (predictive biomarkers) need a better understanding. Those biomarkers are auxiliary tools to select appropriated patients to the right chemotherapy protocol using association with anti-VEGF or anti-EGFR ${ }^{5}$.

Monoclonal antibodies inhibitors of the epidermal growth factor receptor (iEGFR) represent a therapeutic option with proven efficacy for patients with metastatic CRC and wild-type KRAS and NRAS genes. When there are mutations of these genes there is a constitutive activation of the transduction signs from them and the tumor cells become insensitive to the iEGFR ${ }^{5,18}$

It has been proposed the test by PCR and gene sequencing to detect activating mutations at codons 12 and 13 (exon 2), 59 and 61 (exon 3), 117 and 146 (exon 4) of the KRAS and NRAS genes before the start of therapy, due to the inhibitors being high cost drugs and with deleterious effects in patients with mutation ${ }^{3}$. However, the mutation research by PCR and gene sequencing is of high cost, time-consuming, being performed only in large centers ${ }^{18}$.

The EGFR expression by immunohistochemistry has already been investigated to guide the treatment of these patients, but there was disagreement between the expression and the therapeutic response in previous studies ${ }^{22}$. In these studies, it was used the antibody anti-EGFR clone 2-18C9 PharmDX ${ }^{\mathrm{TM} 2,24}$ and considered as positivity only the membrane expression. However, the expression and activation of the receptor occur through early and late regulatory loops, that involve the RAS, attenuating the signal across the whole cascade and/or internalizing the receptor, possibly resulting in dephosphorylation or degradation, providing different degrees of cytoplasmic and membrane marking ${ }^{2}$.

Mutated and constitutively activated KRAS and NRAS may activate the regulatory loops, leading to the internalization of the EGFR and its cytoplasmic marking, interfering in their expression pattern ${ }^{6}$ (Figure 2). In addition, the use of a monoclonal anti-EGFR wild-type antibody (DAK-H1-WT) in CCR has presented significant gain in sensitivity in relation to the antibody used in other studies (EGFR 2-18C9 PharmDX $\left.{ }^{\mathrm{TM}}\right)^{2}$.

Therefore, the validation of the cytoplasmic-membrane expression of the EGFR by immunohistochemistry, predicting the mutational status of the expanded RAS, may allow that the treatment to be established through a diagnostic method less costly and more accessible.

The objective of this study was to propose an analysis method of the EGFR expression, using the monoclonal anti-EGFR DAK-H1-WT antibody, considering membrane/ cytoplasmic marking and evaluate its correlation with the mutational status of the expanded RAS.

\section{METHODS}

This study was approved by Research Ethics Committee from Alberto Rassi Hospital under ID 961.174 - CEPHGG 775/150.

\section{Patient selection}

The archive of the Department of Pathology of Instituto Goiano de Oncologia e Hematologia, Goiânia, GO, Brazil, was researched for the selection of patients who underwent surgical resection of CCR in the period from January 2014 to June 2015. A total of 169 cases with available tumor biological material paraffin block were selected. Thirty samples with signs of autolysis, unsuitable for molecular study or that had not been tested for mutation of the RAS were excluded.

Clinical-pathological data and the mutational status of the expanded RAS in each patient were obtained from our database. Type, histological grade and location were also analyzed in accordance with the criteria established by the World Health Organization in 2010 (http://www. tumourclassification.iarc.who.int) and the staging defined in accordance with the $7^{\text {th }}$ edition of the staging manual of the American Joint Committee on Cancer (http://www. cancerstating.org).

The sample size was calculated based on the population proportion estimate, considering 0.05 of confidence level, test power of $90 \%$ and that patients with RAS mutations represent $45 \%$ of the bearer population of CCR.

\section{PCR reactions and gene sequencing}

All the selected cases were tested, without cost for the study or for the patients, on clinic demand, for the mutation of the expanded RAS by "GENteorienta" (Merck, Darmstadt, Germany) and RASTREAR (AMGEN, Thousand Oaks, USA) programs, in the certificated associated laboratory Progenética (Rio de Janeiro, Brazil). For DNA extraction from paraffin blocks, areas containing at least $50 \%$ of tumor cells were delimited, by a pathologist, in stained slide with $\mathrm{H} \& \mathrm{E}$, for each case. The non-stained slides, corresponding, were immersed in xylol (Sigma, St Louis, USA) and twice in alcohol 100\% (Merck, Darmstadt, Germany), for 5 min each. Tumor areas, which were previously delimited by comparison with the corresponding slides of $\mathrm{H} \& \mathrm{E}$, went through microdissection and were transferred to a tube of microcentrifuge. The DNA was isolated using QIAamp ${ }^{\circledR}$ DNA FFPE Tissue Kit (Qiagen, Hilden, Germany), following the manufacturer instruction. Finally, the DNA was quantified by spectrometry with NanoDrop- $1000^{\circledR}$ (NanoDrop Technologies, ThermoFisher, Waltham, USA ${ }^{\circledR}$ ).

All samples were subjected to DNA sequencing. The exons 2 (codons 12 and 13) and 3 (codon 61) of the KRAS were tested by pyrosequencing with the KRAS Pyro Kit (QIAGEN) commercial kit. The reactions and analysis were performed according to the manufacturer's instructions, using the PyroMark Q24 system (QIAGEN).

The exon 4 of the KRAS and all exons of the NRAS have been tested by the automated Sanger method in a two-sided tape (forward and reverse) in order to evaluate the existence of DNA changes in both the tapes. The primer pairs in this study for NRAS exons 2, 3 and 4, and KRAS exon 4 were all designed using the software primer-BLAST (http://www.ncbi. nlm.nih.gov/tools/primer-blast).

In the analysis of all exons the DNA was subjected to initial denaturation, followed by 35-40 cycles of amplification.

Before the sequencing all amplification products were purified to remove primer, salts, enzymes and dNTP's excesses of the prior reaction.

The sequencing reaction used $1 \mu \mathrm{L}$ of product of each sample added to $0.5 \mu \mathrm{L}$ of Big Dye ${ }^{\circledR}$ Terminator 1.1 sequencing Ready Reaction Mix (Applied Biosystems, Foster City, USA), 3.4 $\mu$ L of Big Dye ${ }^{\oplus}$ Terminator v1.1, v1.3 $5 x$ sequencing buffer (Applied Biosystems), $350 \mathrm{nM}$ of one of the primers ("forward" and "reverse") and $4.78 \mu \mathrm{L}$ of double-distilled sterile water (B. Braun, Melsungen, Germany), for a total volume of $10 \mu \mathrm{L}$. The samples were then subjected to an initial denaturation, 
followed by 35 cycles of synthesis. The sequencing products were purified using Illustra Sephadez ${ }^{\oplus}$ G-50fine (GE Healthcare Life Sciences) and plus $12 \mu \mathrm{L}$ of Hi-DiTM ${ }^{\oplus}$ Formalize (Apllied Biosystems). The products were analyzed in the ABI PRISMTM $310^{\circledR}$ Genetic Analyzer (Applied Biosystems) or in $3500^{\circledR}$ Genetic Analyzer (Applied Biosystems). Electroferrograms were analyzed with the Sequencing Analysis Software v5.4 (Applied Biosystems). All of them have been read at least twice and reviewed manually and with the software Mutation Surveyor Software v4.0.8

\section{Reactions of immunohistochemistry}

The reactions for detection of the EGFR expression were performed in all the selected cases. Two slides of each FFPE sample with cuts of $4 \mu$ of thickness were obtained. One of the slides were stained with $\mathrm{H} \& \mathrm{E}$, for confirmation of morphological data, and the other submitted the reaction of immunohistochemistry by automated Dako LinkAutosteiner $48^{\oplus}$ method (Dako, Glostrup, Denmark), using Dako Flex kit. The samples were subjected to antigen retrieval by controlled heat exposure in a solution of high pH using PTLink ${ }^{\oplus}$ (Dako), endogenous blockade with peroxide, incubation with the primary antibody Epidermal Growth Factor Receptor - Clone DAK-H1-WT - Anti-Human - Monoclonal Mouse (Dako) at a dilution of 1:1000, amplification with LINKER (EnVision FLEX - Dako), reaction with the polymer (EnVision Flex/HRP) for 20 min, revelation of chromogen for 5 min and counterstaining with hematoxylin (EnVision FLEX) for 5 min.

\section{Analysis of the immunohistochemistry slides}

The slides reaction of each case was evaluated by two pathologists in consensus. We used a classification score of the membrane and cytoplasm marking (Table 1). For membrane marking the score ranged from 0 to +3 . The sample should contain strong and complete membrane marking in more than $50 \%$ of neoplastic cells to be considered +3 (Figure 2D). The focal and weak membrane marking in any quantity of cells was considered +1 (Figure $2 \mathrm{~A}$ ) and the rest of the cases were considered +2 (Figures $2 \mathrm{~B}$ and $2 \mathrm{C}$ ). The cytoplasmic marking ranged from 0 to -3 , whereas since the absence of marking $(0)$ until the strong and diffuse marking ( -3 , Figure 2). The cases with large negative areas, larger than $30 \%$ of the neoplasia, both membrane and cytoplasm were also considered, independently of the marking, assigning score of -1 to these cases (Table 1 ).

The cases were grouped according to scores sum into 3 classes. "positive", "negative" and "uncertain". The samples with results 2 and 3 were allocated in the "positive" class (Figure 1). Those with 0 and 1 results were assigned in the "uncertain" class. Those with negative results were assigned in the "negative" class.

\section{Statistical analysis}

The statistical analysis was performed using the software SPSS 18.0 (SPSS Inc., Chicago, IL, USA). To evaluate the statistical significance, it was applied the chi-square test considering $p<0.001$.

\section{RESULTS}

Clinical-pathological correlations of the mutation of the expanded RAS and of the EGFR expression

The average age of the 139 patients was 61.8 years with a standard deviation of 13.9 years, being 26 (19.5\%) less than 50 years and $10(7.5 \%)$ less than 40 . There was no disparity of gender, being $52.9 \%$ of men and $47.1 \%$ of women (Table 2).

No significant correlation was found between the mutational status of the expanded RAS and the EGFR expression in comparison to age ( $p=0.541$ and 0.652 respectively), gender $(p=0.348$ and 0.540$)$, location $(p=0.393$ and 0.098$)$, histological type $(p=0.199$ and 0.697$)$, histological grade $(p=0.900$ and 0.182$)$ and stage $(p=0.533$ and 0.053 , Table 2$)$.

The mutation of the expanded RAS was detected in 78 (56.1\%) of the 139 cases with CCR tested by pyrosequency and by automatized Sanger method. Of these, 72 cases $(51.79 \%)$ had mutations in the KRAS gene, with 63 cases (45.3\%) with mutations in the codons 12 and 13 (exon 2), four cases (2.8\%) with mutations in codon 61 (exon 3 ) and five cases (3.59\%) with mutations in codon 146 (exon 4). No mutations were detected in codons 59 (exon 3) and 117 (exon 4) in the KRAS gene.

The research with the NRAS gene has revealed mutations in six cases (4.3\%) in the codons 12 and 61 (exons 2 and 3), with no mutation being detected in the codon 13 (exon 2), in the codon 59 (exon 3) and in the codons 117 and 146 (exon 4).

The immunohistochemistry slides analysis revealed marking of exclusive membrane in only four cases $(2.8 \%)$ and of exclusive cytoplasm, in other four (2.8\%). All cases with exclusive marking of membranes showed wild-type RAS and all cases marked with unique cytoplasmic showed mutated RAS. The rest of the cases showed positivity for both membrane and cytoplasm at variables intensifies. Twentythree cases (16.5\%) were allocated in the "positive" group (scores 2 and 3 ). In the "negative" group (negative scores) were allocated 49 cases (35.2\%) and in the group "uncertain" (scores 0 and 1 ) were allocated 67 cases $(48.2 \%$, Table 3 ). The direct correlation of the EGFR expression stratified into classes "positive", "negative" and "uncertain" in comparison to the mutational status of the expanded RAS showed a strong association between groups ( $<<0.001$, Table 3$)$. Of the 23 cases of the "positive" class, 21 (91.3\%) showed the wild RAS gene for the researched mutations. Of the 49 cases of "negative" class, 41 (83.7\%) presented mutation in the expanded RAS panel. The 67 cases allocated as "uncertain" presented parity in the findings with 32 cases of $(47.8 \%)$ RAS wild and 35 mutated cases (52.2\%).

Test validation EGFR membrane-cytoplasmic expression is shown in Table 4.

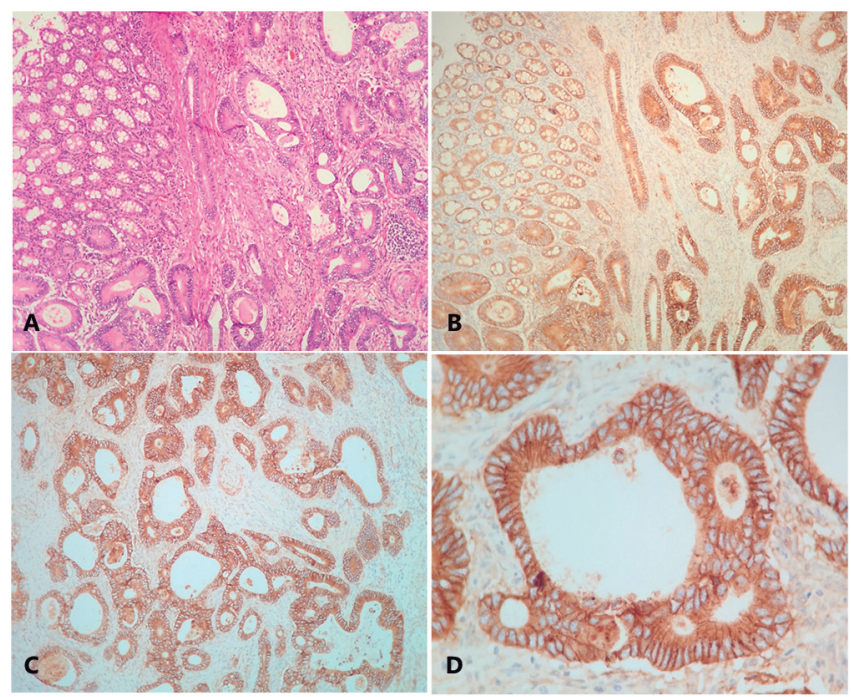

FIGURE 1-A) Grade II CCR with normal mucosa area on the upper left corner (H\&E 40x); B) immunohistochemistry for EGFR showing strong marking of the membrane and weak of the cytoplasm (M3C1) Score 2 (positive) Wild-type RAS; $C$ and D) details in other areas of the same case showing homogeneous pattern of the M3C1 marking 
TABLE 2 - Clinical-pathological correlation between EGFR and RAS

\begin{tabular}{|c|c|c|c|c|c|c|c|}
\hline & \multicolumn{3}{|c|}{$\operatorname{EGFR}(\mathrm{n} / \%)$} & \multicolumn{4}{|c|}{ RAS (n/\%) } \\
\hline & Positive & Negative & Uncertain & $p$ & Savage & Mutated & $p$ \\
\hline \multicolumn{8}{|l|}{ Age } \\
\hline$<40$ years & $1 / 10.0$ & $2 / 20.0$ & $7 / 70.0$ & \multirow{3}{*}{0.65} & $5 / 50.0$ & $5 / 50.0$ & \multirow{3}{*}{0.54} \\
\hline 40 to 50 years & $1 / 6.3$ & $6 / 37.6$ & $9 / 56.3$ & & $5 / 31.36$ & $11 / 68.8$ & \\
\hline$>=50$ years & $20 / 18.7$ & $38 / 35.5$ & $49 / 45.8$ & & $48 / 49.9$ & $59 / 55.1$ & \\
\hline \multicolumn{8}{|l|}{ Gender } \\
\hline Male & $15 / 20.5$ & $23 / 31.5$ & $35 / 47.9$ & \multirow{2}{*}{0.54} & $35 / 47.9$ & $38 / 52.1$ & \multirow{2}{*}{0.34} \\
\hline Female & $8 / 12.3$ & $26 / 40.0$ & $31 / 47.7$ & & $26 / 40.0$ & $39 / 60.0$ & \\
\hline \multicolumn{8}{|l|}{ Location } \\
\hline Right Colon & $7 / 14.6$ & $15 / 31.3$ & $26 / 54.2$ & \multirow{3}{*}{0.09} & $18 / 37.5$ & $62.5 / / 30$ & \multirow{3}{*}{0.39} \\
\hline Left Colon & $5 / 17.9$ & 9/32.2 & $14 / 50.0$ & & $15 / 53.6$ & $13 / 46.4$ & \\
\hline Recto-sigmoid & $11 / 17.5$ & $25 / 39.7$ & $27 / 42.9$ & & $28 / 44.4$ & $35 / 55.6$ & \\
\hline \multicolumn{8}{|l|}{ Histological type } \\
\hline Tubular & $20 / 17.1$ & $43 / 36.7$ & $54 / 46.2$ & \multirow{3}{*}{0.69} & $54 / 46.2$ & $63 / 53.8$ & \multirow{3}{*}{0.19} \\
\hline Mucinous & $2 / 25.0$ & $1 / 12.5$ & $5 / 62.5$ & & $4 / 50.0$ & $4 / 50.0$ & \\
\hline Tubular-mucinous & $1 / 7.1$ & $5 / 35.7$ & $8 / 57.1$ & & $3 / 21.4$ & $11 / 78.6$ & \\
\hline \multicolumn{8}{|l|}{ Histological degree } \\
\hline 1 & $1 / 14.3$ & $2 / 28.6$ & $6 / 24.0$ & \multirow{3}{*}{0.18} & $3 / 42.9$ & $4 / 57.1$ & \multirow{3}{*}{0.90} \\
\hline 2 & $16 / 15.0$ & $41 / 38.3$ & $6 / 24.0$ & & $46 / 43.0$ & $61 / 57.0$ & \\
\hline 3 & $6 / 24.0$ & $50 / 46.7$ & $13 / 52.0$ & & $12 / 48.0$ & $13 / 52.0$ & \\
\hline \multicolumn{8}{|l|}{ Stage } \\
\hline 0 & $0 / 0.0$ & $2 / 11.0$ & $6 / 9.0$ & \multirow{9}{*}{0.05} & $4 / 6.6$ & $4 / 5.1$ & \multirow{9}{*}{0.53} \\
\hline I & $1 / 4.3$ & $6 / 33.1$ & $9 / 13.4$ & & $4 / 6.6$ & $12 / 15.4$ & \\
\hline IIA & $8 / 34.8$ & $14 / 54.7$ & $16 / 23.9$ & & $16 / 26.2$ & 22/28.2 & \\
\hline IIB & $0 / 0.0$ & $1 / 2.7$ & $5 / 7.5$ & & $3 / 4.9$ & $3 / 3.8$ & \\
\hline$\| C$ & $3 / 13.0$ & $1 / 2.7$ & $0 / 0.0$ & & $3 / 4.9$ & $1 / 1.3$ & \\
\hline IIIA & $0 / 0.0$ & $3 / 8.1$ & $1 / 1.5$ & & $3 / 4.9$ & $1 / 1.3$ & \\
\hline IIIB & $5 / 21.7$ & $15 / 40.5$ & $22 / 32.8$ & & $18 / 29.5$ & $24 / 30.8$ & \\
\hline IIIC & $5 / 21.7$ & $7 / 18.9$ & $8 / 11.9$ & & $9 / 14.8$ & $11 / 14.1$ & \\
\hline IV & $1 / 4.3$ & $0 / 0.0$ & $0 / 0.0$ & & $1 / 1.6$ & $0 / 0.0$ & \\
\hline
\end{tabular}

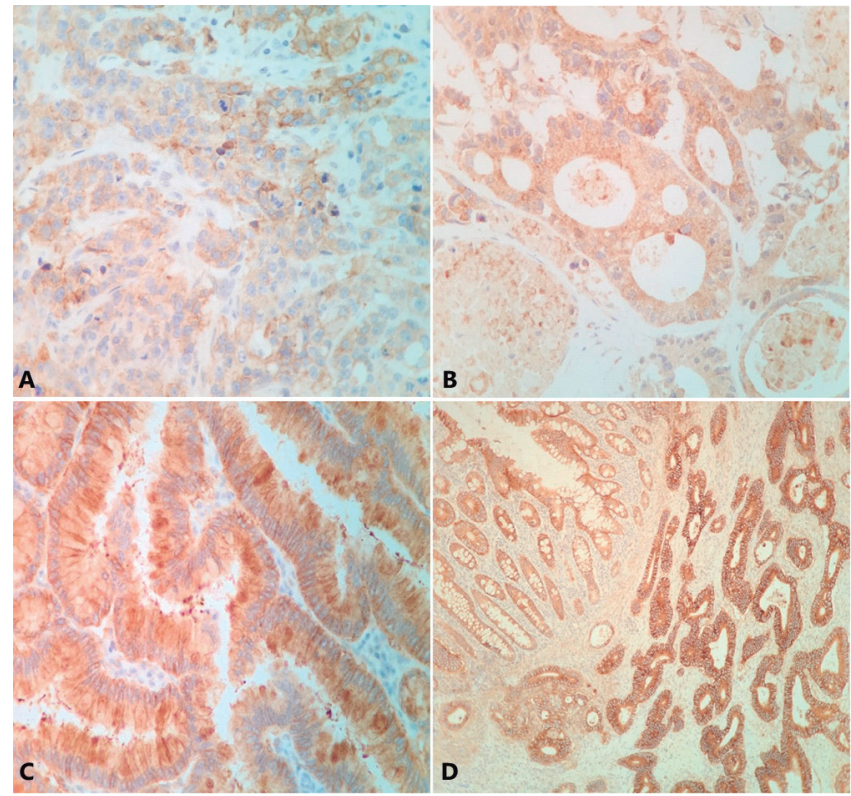

FIGURE 2 - A) Immunohistochemistry for EGFR showing weak marking of membrane and cytoplasm (M1C1) score 0 (uncertain) wild-type RAS; B) negative membrane and cytoplasm 2+ (MOC2) score -2 (negative) mutated RAS KG12A; C) membrane +1 and cytoplasm +3 (M1C3) score -2 (negative) mutated RAS KG12V; D) membrane +3 and cytoplasm +1 (M3C1) score 2 (positive) wild-type RAS. On the upper left corner normal mucosa with tenuous cytoplasmic-membrane marking.
TABLE 1 - Score proposed for analysis of the cytoplasmic-membrane expression of the EGFR by immunohistochemistry

\begin{tabular}{ll}
\multicolumn{1}{c}{ Membrane $(\mathrm{m})$} & \multicolumn{1}{c}{ Criteria } \\
Score $3+$ & Strong and complete in more than $50 \%$ of the cells \\
Score 2+ & Intermediate between score $1+$ and $3+$ \\
Score $1+$ & Focal and weak in any quantity of cells \\
Score 0 & Absence of membrane marking \\
\hline Cytoplasm (c) & Criteria \\
\hline Score 0 & Absence of cytoplasmic marking \\
Score 1- & Weak in any quantity of cells \\
Score 2- & Intermediate in more than $10 \%$ of the cells \\
Score 3- & Strong in more than $10 \%$ of the cells \\
\hline Negative areas (na) & Criteria \\
\hline Score 0 & Any marking in more than $70 \%$ of the cells \\
Score 1- & Absence in making in more than $30 \%$ of the cells \\
Result & Criteria \\
Positive & $\mathrm{M}+\mathrm{C}+\mathrm{NA} \geq 2$ \\
Negative & $\mathrm{M}+\mathrm{C}+\mathrm{NA} \leq 1-$ \\
Uncertain & $\mathrm{M}+\mathrm{C}+\mathrm{NA}=0$ or 1.
\end{tabular}

TABLE 3 - Correlation between the EGFR groups and the mutational condition of the RAS

\begin{tabular}{|c|c|c|c|c|c|c|c|}
\hline \multicolumn{8}{|c|}{ EGFR } \\
\hline \multirow{2}{*}{ RAS } & \multicolumn{2}{|c|}{ Positive } & \multicolumn{2}{|c|}{ Negative } & \multicolumn{2}{|c|}{ Uncertain } & \multirow{2}{*}{$p^{*}$} \\
\hline & $\mathrm{n}$ & $\%$ & $\mathrm{n}$ & $\%$ & $n$ & $\%$ & \\
\hline Savage & 21 & 91.3 & 8 & 16.3 & 32 & 47.8 & \multirow{3}{*}{$<0.001$} \\
\hline Mutated & 2 & 8.7 & 41 & 83.7 & 35 & 52.2 & \\
\hline Total & 23 & 100.0 & 49 & 100.0 & 67 & 100.0 & \\
\hline
\end{tabular}


TABLE 4 - Test validation EGFR membrane-cytoplasmic expression by immunohistochemistry considering only the positives and negatives

\begin{tabular}{|c|c|c|c|}
\hline \multirow{2}{*}{ EGFR } & \multicolumn{3}{|c|}{ RAS } \\
\cline { 2 - 4 } & Savage & Mutated & Total \\
\hline Positive & 21 & 2 & 23 \\
\hline Negative & 8 & 41 & 49 \\
\hline Total & 29 & 43 & 72 \\
\hline
\end{tabular}

Sensibility $=72.4 \%$; specificity $=95.3 \%$; accuracy $=86.1 \%$; predictive positive value $=83.6 \%$; predictive negative value $=86.1 \%$

\section{DISCUSSION}

\section{Relation between EGRF and RAS}

Our study shows that the cytoplasmic-membrane analysis of the EGFR stratified into the classes "positive", "negative" and "uncertain" based on the regulation of the receptor is able to predict the mutational status of the RAS in $51.7 \%$ of the analyzed cases, with $86.1 \%$ of accuracy $(p<0.001$, Table 4$)$.

The EGFR activates the MAPK pathway through the RAS. The same will result in the transcription of various growth factors; however, there is also the production of MIG- 6 which acts by activating the internalization and degradation of the receptor ${ }^{2}$. Studies investigating the direct relationship between EGFR amplification and expression and the mutation status of the KRAS, showed no relationship between these two components ${ }^{8}$. Nevertheless, they were performed in small series, someanalyzed only the amplification ${ }^{8}$ and the others studied the expression by analysis of high and low affinity for binding to the receptor ${ }^{19}$, and that there have been no studies, like ours, comparing the EGFR cytoplasmic-membrane immunohistochemistry expression using the antibody clone (DAK$\mathrm{H} 1-\mathrm{WT}$ ) and the mutational status of the expanded RAS.

\section{Gene and EGFR receptor}

EGFR is a transmembrane receptor, part of the Erb's family. Has an extracellular domain that can be selectively activated by epidermal growth factor(EGF) and alpha growth transforming factor (TGF- $\alpha$ ), leading to dimerization and activation of the receptor. Once activated the receptor suffers auto phosphorylation of its tyrosine-kinase intra-cytoplasmic domain there in cascade activate the RAS/RAF/MEK/MAPK and therefore the nuclear transcription factors by activation and regulation of genes responsible for cellular replication, angiogenesis, differentiation, etc. Expressed in lung, colon, breast, head and neck, ovarian cancer, pancreas, bladder and kidney tumors ${ }^{12,26}$.

The expression and activation of the receptor have early and late regulatory loops, acting on signal attenuation across the cascade and/or in the internalization of the receptor. As a result, there is dephosphorization or degradation of the EGFR $23,3,18$, allowing its detection in both membrane and cytoplasm, justifying the cytoplasmic-membrane joint analysis in the $\mathrm{IHC}$ for determination of the marking score ${ }^{14}$.

The mutations of the EGFR gene are uncommon in colorectal carcinomas, enabling the use of the wild-typeclone DAK-H1-WT forthe research of the receptor. There are studies by immunohistochemistry showing EGFR expression in $60-80 \%$ of the CCR ${ }^{25}$; however, only $24 \%$ of these tumors presented amplification of the EGFR gene ${ }^{23}$. Clinical studies showed a discrepancy between the EGFR expression and the therapeutic response to the receptor inhibitors ${ }^{17}$, and that up to $25 \%$ of the tumors with negative expression for EGFR are responsive to Cetuximab (iEGFR) ${ }^{4}$. But the vast majority of these studies used the kit PharmDx ${ }^{\mathrm{TM}}$ with the antibody EGFR2.5 in the immunohistochemistry reactions for detection of EGFR, contrasting with the significant increase of sensitivity in these receptors using the clone of antibody DAK-H1-WT that detects only wild-type receptors ${ }^{26}$. Ourstudy showed $97.2 \%$ ofEGFR membrane expression, confirming the great gain in sensitivity with this clone.

While some studies showed a relationship between the expression and the degree of the tumor or the survival of the patients, 20, others did not have similar results ${ }^{25}$, as well as in our analysis in which no significant correlation was found between the EGFR expression in comparison to age, gender, location, histological type, histological grade and stage.

A study with 47 patients showed no significant of amplification of the gene in the therapeutic response ${ }^{9}$. Another showed that the $17 \%$ of the patients with wild KRAS and amplification of the EGFR gene treated with Cetuximab had therapeutic response ${ }^{13}$. Similar percentage to the "positive" cytoplasmic-membrane score of our study, in which $16.5 \%$ of the cases showed a strong correlation with the wild expanded RAS, suggesting that there may be a correlation between this study group and the amplification of the gene. Unlike the "uncertain" group where the cases can be amplified but not hyper-expressed due to inhibition by the regulatory loops of the mutated RAS, constitutively activated, or cases in which there is no amplification and therefore doubtful expression of the receptor. Further analysis correlating the cytoplasmic-membrane to the amplification of the EGFR gene and the mutational status of the RAS are needed to clarify these issues.

\section{Genes and KRAS and NRAS proteins}

KRAS and NRAS are members of the family of RAS oncogenes. They are binder proteins, initiator of the MAPK pathway after activation by the EGFR and codified by specific RAS proto-oncogenes. The HRAS, third member of the RAS family, is rarely mutated in CCR ${ }^{6}$. Somatic mutations of these genes are early event in carcinogenesis, present in $40 \%$ to $45 \%$ of CCR, usually being mutually exclusive ${ }^{15,21}$. This percentage is lower than one found in our analysis (56.1\%) that considered all the exons already recommended in current guidelines ${ }^{5,18}$. Our study also showed a mutation of the NRAS in $4.3 \%$ of the cases, value also higher than the $2 \%$ found in a previous study ${ }^{18}$.

Once mutated, these proteins stimulate the EGFR/MAPK pathway constitutively, therefore leading to resistance to treatment with inhibitors of this receptor (Cetuximab and Panitumumab) 1,11,14,28. Cases with wild KRAS presented a clinical benefit with the use of inhibitors of EGFR alone and in combination with chemotherapy ${ }^{16,27}$. However, only $13-17 \%$ of the tumors with wild KRAS responded ${ }^{1,11}$. Phase 3 randomized clinical studies showed the lack of response in patients with mutations in the KRAS or NRAS ${ }^{28}$. BRAF mutations (p.V600E), molecule also associated with the signaling of RAS-EGFR has been implicated in a proportion of non-responsive patients ${ }^{21,27}$. These mutations could justify cases of the "negative" group of our study in which the RAS mutation was not detected, since these genes are also linked to the receptor regulatory loops, which may decrease its expression.

There is also a parallel pathway of the PTEN/PIK3CA/AKT - EGFR that inhibits the apoptosis of neoplastic cells, being that the PTEN (Phosphatase and Tensin Homologue Gene) inhibits this pathway when using the PIK3CA as substrate. Mutations in the pathway lead to hyper-phosphorylation of the AKT, constitutive inhibition of apoptosis and consequent failure in the response of the EGFR inhibitors ${ }^{10}$.

The limitations of this study are: small sample; the analysis of the EGFR expression was performed by only two pathologists; the mutational status of the RAS was available during the expression analysis; the mutational status of the BRAF and PIK3CA genes were not contemplated in the study.

This study is pioneer in the analysis of the EGFR expression by immunohistochemistry, using a cytoplasmic-membrane marking score stratified into the classes "positive", "negative" and "uncertain", based on the recycling of this receptor triggered by regulation loops, it is able to predict the mutational status of the RAS in $51.7 \%$ of cases with $86.1 \%$ of accuracy. However, further studies are needed to determine the reason why almost half of the cases are still uncertain. Analyzes contemplating the EGFR amplification and mutations in other genes of the EGFR/MAPK cascade as BRAF and PIK3CA, may allow a better stratification of this population. 
CONCLUSIONS

The cytoplasmic-membrane analysis of the EGFR expression stratified into "positive", "negative" and "uncertain" predicts mutational status of the RAS in $51.7 \%$ of the cases $(p<0.001)$, with $86.1 \%$ of accuracy.

\section{REFERENCES}

1. Amado RG, Wolf M, Peeters M, Van Cutsem E, Siena S, Freeman DJ, et al. Wild-type KRAS is required for panitumumab efficacy in patients with metastatic colorectal cancer. J Clin Oncol. 2008;26(10):1626-1634.

2. AvrahamR, YardenY.FeedbackregulationofEGFRsignalling:decisionmaking by early and delayed loops. Nature Rev Mol Cell Biol.2011;12(2):104-117.

3. Carethers JM, Jung BH Genetics and genetic biomarkers in sporadic colorectal cancer. Gastroenterology. 2015;149(5):1177-1190.e3.

4. Chung KY, ShiaJ, Kemeny NE, ShahM, SchwartzGK, Tse A, etal. Cetuximab shows activity in colorectal cancer patients with tumors that do not express theepidermal growthfactorreceptorbyimmunohistochemistry. J Clin Oncol. 2005;23(9):1803-1810.

5. Das V, Kalita J, Pal M. Predictive and prognostic biomarkers in colorecta cancer: A systematic review of recent advances and challenges. Biomed Pharmacother. 2017;87:8-19.

6. Fernández-Medarde A, Santos, E. Ras in cancer and developmental diseases. Genes Cancer. 2011;2(3):344-358.

7. GoldsteinNS,ArminM.Epidermalgrowthfactorreceptorimmunohistochemical reactivity in patients with American Joint Committee on cancer stage IV colon adenocarcinoma. Cancer. 2001;92(5):1331-1346.

8. Heinemann V, Stintzing S, Kirchner T, Boeck S, Jung A. Clinical relevance of EGFR-and KRAS-status in colorectal cancer patients treated with monoclonal antibodies directed against the EGFR. Cancer Treat Rev. 2009;35(3):262-271.

9. Italiano A, Follana P, Caroli FX, Badetti JL, Benchimol D, Garnier G, et al. Cetuximab shows activity in colorectal cancer patients with tumors for which FISH analysis does not detect an increase in EGFR gene copy number. Ann Surg Oncol. 2008;15(2):649-654.

10. Jhawer M, Goel S, Wilson AJ, Montagna C, Ling YH, Byun DS, et al. PIK3CA mutation/PTEN expression status predicts response of colon cancer cells to the epidermal growth factor receptor inhibitor cetuximab. Cancer Res. 2008;68(6):1953-1961.

11. Karapetis CS, Khambata-Ford S, Jonker DJ, O'Callaghan CJ, Tu D, Tebbutt NC, Simes RJ, et al. K-ras mutations and benefit from cetuximab in advanced colorectal cancer. N Engl J Med. 2008;359(17):1757-1765.

12. Krasinskas AM. EGFR signaling in colorectal carcinoma. Pathol Res Int. 2011; Article ID 932932, 6 pages.

13. Laurent-Puig P, Cayre A, Manceau G, Buc E, Bachet JB, Lecomte T, et al Analysis of PTEN, BRAF, and EGFR status in determining benefit from cetuximab therapy in wild-type KRAS metastatic colon cancer. J Clin Oncol. 2009;27(35):5924-5930.
14. Lee JW, Soung YH, Kim SY, Park WS, Nam SW, Lee JY, et al. Absence of EGFR mutation in the kinase domain in common human cancers besides non-small cell lung cancer. Int J Cancer, 2005;113(3):510-511.

15. LeslieA, CareyFA, PrattNR, SteeleRJC.Thecolorectaladenoma-carcinoma sequence. Br J Surg. 2002;89(7):845-860.

16. Lièvre A, Bachet JB, Boige V, Cayre A, Le Corre D, Buc E, et al. KRAS mutationsasanindependent prognosticfactor in patientswith advanced colorectal cancertreated with cetuximab.JClinOncol.2008;26(3):374-379.

17. Loupakis, F., Ruzzo, A., Cremolini, C. Vincenzi B, Salvatore L, Santini D, et al. KRAS codon 61, 146 and BRAF mutations predict resistance to cetuximab plus irinotecan in KRAS codon 12 and 13 wild-type metastatic colorectal cancer. Br J Cancer. 2009;101(4):715-721.

18. Mármoll,Sánchez-de-Diego C, DiesteAP, CerradaE, YoldiMJR.Colorecta Carcinoma: A General Overview and Future Perspectives in Colorectal Cancer. Int J Mol Sci. 2017;18:197.

19. Milano G, Etienne-Grimaldi MC, Dahan L, Francoual M, Spano JP Benchimol D, et al. Epidermal growth factor receptor (EGFR) status and K-Rasmutationsincolorectal cancer.Ann Oncol.2008;19(12):2033-2038.

20. Resnick MB, Routhier J, Konkin T, Sabo E, Pricolo VE. Epidermal growth factor eeceptor, c-MET, $\beta$-catenin, and p53 expression as prognostic indicators in stage II colon cancer: a tissue microarray study. Clin Cancer Res. 2004;10(9):3069-3075.

21. Roth AD, Tejpar S, Delorenzi M, Yan P, Fiocca R, Klingbiel D, Dietrich D, et al. Prognostic role of KRAS and BRAF in stage II and III resected colon cancer: results of the translational study on the PETACC-3, EORTC 40993, SAKK 60-00 trial. J Clin Oncol. 2010;28(3):466-474.

22. SaltzLB, MeropolNJ, LoehrerPJ, NeedleMN, KopitJ, MayerRJ.Phaselltrial of cetuximab in patients with refractory colorectal cancer that expresses theepidermal growth factorreceptor.JClin Oncol.2004;22(7):1201-1208.

23. Shia J, Klimstra DS, Li AR, Qin J, Saltz L, Teruya-Feldstein J, et al. Epidermal growth factor receptor expression and gene amplification in colorectal carcinoma:animmunohistochemicaland chromogenicinsituhybridization study. Mod Pathol. 2005;18(10):1350-1356.

24. Shiogama K, Wongsiri T, Mizutani Y, Inada KI, TsutsumiY. High-sensitivity epidermal growth factor receptor immunostaining for colorecta carcinomas, compared with EGFR PharmDxTM: A study of diagnostic accuracy. Int J Clin Exp Pathol. 2013;6(1):24-30.

25. Spano JP, Fagard R, Soria JC, Rixe O, Khayat D, Milano G. Epidermal growth factor receptor signaling in colorectal cancer: preclinical data and therapeutic perspectives. Ann Oncol, 2005;16(2):189-194.

26. Sullivan KM, Kozuch PS. Impact of KRAS mutations on management of colorectal carcinoma. Pathol Res Int. 2011; Article ID 219309, 11 pages

27. Van Cutsem E, Köhne CH, Láng I, Folprecht G, Nowacki MP, Cascinu S et al. Cetuximab plus irinotecan, fluorouracil, and leucovorin as first-line treatment for metastatic colorectal cancer: updated analysis of overall survival according to tumor KRAS and BRAF mutation status. J Clin Oncol. 2011;29(15):2011-2019.

28. Van Cutsem E, Lenz HJ, Köhne CH, Heinemann V, Tejpar S, Melezínek I, et al. Fluorouracil, leucovorin, and irinotecan plus cetuximab treatment and RAS mutations in colorectal cancer. J Clin Oncol. 2015;33(7):692-700. 